\title{
Characteristics of cancer patients with COVID-19 in a cancer hospital
}

\author{
Demis N. Lipe ${ }^{1}$, Ahmed Elsayem ${ }^{1}$, Maria T. Cruz-Carreras ${ }^{1}$, Jomol Thomas $^{1}$, Adianes Feliciano ${ }^{2}$, \\ Jenny Ren ${ }^{3}$, Susan M. Gaeta ${ }^{1}$, Eva Rajha ${ }^{1}$, Elisabet Manasanch ${ }^{4}$, Ed Kheder ${ }^{5}$, Patricia Brock ${ }^{1}$, \\ Cielito Reyes-Gibby ${ }^{1,6}$
}

${ }^{1}$ Department of Emergency Medicine, The University of Texas MD Anderson Cancer Center, Houston, TX, USA; ${ }^{2}$ Department of Emergency Medicine, Baylor College of Medicine, Houston, TX, USA; ${ }^{3}$ Baylor College of Medicine, Houston, TX, USA; ${ }^{4}$ Department of LymphomaMyeloma, The University of Texas MD Anderson Cancer Center, Houston, TX, USA; ${ }^{5}$ Department of General Internal Medicine, The University of Texas MD Anderson Cancer Center, Houston, TX, USA; ${ }^{6}$ Department of Biostatistics, The University of Texas MD Anderson Cancer Center, Houston, TX, USA

Contributions: (I) Conception and design: DN Lipe, C Reyes-Gibby; (II) Administrative support: P Brock; (III) Provision of study materials or patients: J Ren, E Rajha, A Feliciano, E Kheder, E Manasanch, A Elsayem, J Thomas, MT Cruz-Carreras, SM Gaeta, P Brock; (IV) Collection and assembly of data: J Thomas, MT Cruz-Carreras, DN Lipe; (V) Data analysis and interpretation: DN Lipe, C Reyes-Gibby, A Elsayem; (VI) Manuscript writing: All authors; (VII) Final approval of manuscript: All authors.

Correspondence to: Demis N. Lipe, MD, MS. Department of Emergency Medicine, Unit 1468, The University of Texas MD Anderson Cancer Center, 1515 Holcombe Blvd, Houston, TX 77030, USA. Email: dnlipe@mdanderson.org.

Background: Cancer patients are vulnerable to the coronavirus disease 2019 (COVID-19) given their compromised immune system. The purpose of this study was to describe the presenting symptoms, inpatient stay trajectory, and survival outcomes, for cancer patients infected with COVID-19; who presented to the emergency department (ED) of a single center during the early months of the pandemic.

Methods: We reviewed the electronic medical records of all cancer patients diagnosed with COVID-19 at our institution for demographic information, clinical presentation, laboratory findings, treatment intervention and outcomes. All patients had at least 14 days of follow-up. We determined their survival outcomes as of August 5, 2020.

Results: Twenty-eight cancer patients were diagnosed with COVID-19, and 16 (57\%) presented to the ED during the study period. The median age of patients who presented to the ED was 61 years, $69 \%$ were women, and the median length of hospitalization was 11 days. There was no difference between the groups (ED vs. no ED visit) for demographics, treatment status or solid tumor versus hematologic malignancies or treatments. Dyspnea was a significant symptom with $67 \%$ of ED patients experiencing it versus only $17 \%$ of those that did not come to the ED $(\mathrm{P}=0.009)$. Do not resuscitate orders were initiated in eight patients, as early as two days from ED presentation and two of these patients died, while $88 \%$ of patients were discharged alive.

Conclusions: Most cancer patients with COVID-19 infection admitted though the ED experienced dyspnea and were discharged from the hospital. We did not notice a statistically significant difference between cancer types or type of therapy. A broad differential is of utmost importance when caring for cancer patients with COVID-19 due to the complexity of this population. Early goals of care discussion should be initiated in the ED.

Keywords: Cancer; coronavirus disease 2019 (COVID-19); SARS-CoV-2; end of life care; do not resuscitate; emergency department (ED)

Submitted Jul 20, 2020. Accepted for publication Oct 26, 2020.

doi: 10.21037/apm-20-1447

View this article at: http://dx.doi.org/10.21037/apm-20-1447 


\section{Introduction}

The coronavirus disease 2019 (COVID-19), continues to increase globally with more than 33 million cases and over one million related deaths-worldwide (1). Cancer patients, who tend to be older, have comorbidities, and have deficient or compromised immune systems, are expected to be particularly vulnerable to COVID-19 $(2,3)$. These patients' care can be complicated by the early and late toxicities of their cancer treatments. Early studies reported that patients with cancer are more likely to need mechanical ventilation, be admitted to the intensive care unit, and die than patients without cancer $(3,4)$. Underscoring this finding, an analysis of 355 patients who died from COVID-19 in Italy showed that up to $20.3 \%$ of the patients had active cancer (5).

The most frequently reported presenting symptoms of COVID-19 are fever, cough, shortness of breath or fatigue (3,5-9). These symptoms are also common to cancer patients without COVID-19 infection presenting to the emergency department (ED). Whether specific symptoms or findings in cancer patients will suggest COVID-19 infection in ED is not clear. Recently, a risk stratification tool was proposed for use in the ED (10), but there is no specific prognostic score to assist with treatment prioritization decisions in cancer patients. This lack of understanding has important implications for oncologic emergency medicine, whose practitioners are faced with the challenge of rapidly identifying the risk profiles of cancer patients with COVID-19 and determining the appropriate timing of interventions for the disease.

Given the increasing demands on the healthcare system, it is important to understand the role of addressing end of life care early in the care of the cancer patient. The purpose of this study was to describe the clinical characteristics of cancer patients with COVID-19, including the inpatient stay, clinical outcomes, goals of care and resuscitation preferences in a tertiary cancer center over the first months of the outbreak.

We present the following article in accordance with the STROBE reporting checklist (available at http://dx.doi. org/10.21037/apm-20-1447).

\section{Methods}

\section{Study setting and patient population}

This retrospective observational study included all cancer patients between March 10, 2020, and April 10, 2020, for whom reverse-transcriptase polymerase chain reaction (RTPCR) analysis of a nasopharyngeal swab or bronchoalveolar lavage specimen revealed SARS-CoV-2 infection. The turnaround time at our institution for the RT-PCR test is approximately 24 hours, therefore results were not immediately available in the ED. All patients received an infectious disease consultation, and were followed for at least 14 days after diagnosis; we determined their survival outcomes as of August 5, 2020. Excluded patients were those without cancer or without positive SARS-CoV-2 test. This study was conducted in accordance with a clinical research protocol (\# 2020-0348) approved by MD Anderson Cancer Center's Institutional Review Board, and the study conformed to the provisions of the Declaration of Helsinki (as revised in 2013). Written informed consent was waived as this was a chart review study.

\section{Data collection}

Data obtained from the electronic medical record included: demographics; symptoms leading to COVID-19 testing; comorbidities; cancer diagnoses and treatment; vital signs at presentation to the ED; radiographic and laboratory test results; clinical outcomes. All laboratory values were obtained from the day of presentation/admission.

Chart reviews and data abstraction were independently conducted by two trained investigators (DNL and MTCC), who resolved any disagreements through discussion. A third, monitored investigator (JT) reviewed 20\% of the charts for accuracy and consistency. A standardized abstraction form to guide data collection as well as precise definitions of variables were provided to avoid misclassification bias.

\section{Statistical analysis}

Descriptive statistics were used to summarize the sociodemographic and clinical characteristics of the study population. Continuous variables were reported as medians and interquartile ranges, or means and standard deviations, while categorical values were analyzed as counts and percentages. Differences between patients presenting to the ED and those getting outpatient testing were assessed using independent $t$-test, Student Pearson's chi-squared test, or Fisher's exact test where appropriate. Statistical Package for Social Sciences (SPSS) statistical software 24 was used for all analyses (IBM, Armonk, NY, USA). 


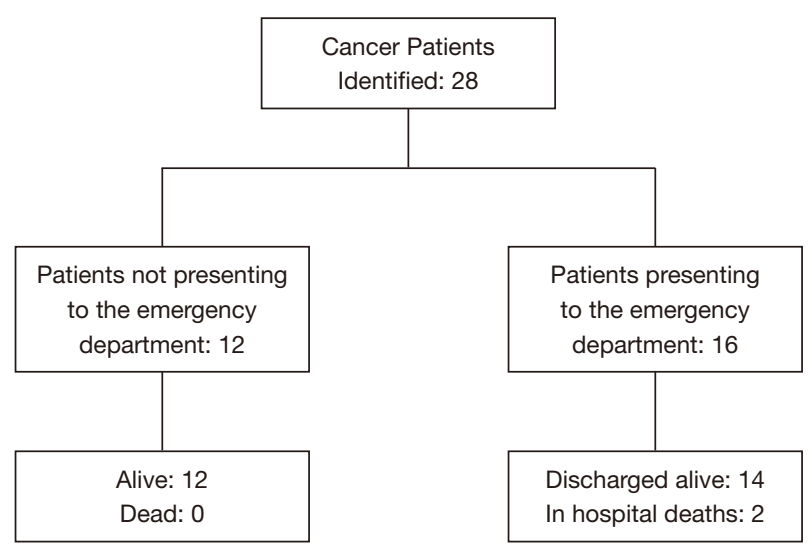

Figure 1 Flowchart of patient selection and outcomes.

\section{Clinical definitions}

For this study, we defined "severe outcome" as death, needing vasopressor support or mechanical ventilation. Furthermore, patients who developed hypoxemia were initially given supplemental oxygen by nasal cannula; those who required oxygen at a rate of more than $6 \mathrm{~L} / \mathrm{min}$ were switched to a non-rebreather mask. Tocilizumab $(8 \mathrm{mg} / \mathrm{kg})$, a monoclonal antibody that competitively inhibits the binding of interleukin-6 to its receptor, was administered to any patient on nasal cannula who required more than $3 \mathrm{~L}$ $\mathrm{O}_{2} /$ min to maintain an $\mathrm{O}_{2}$ saturation of $>92 \%$; if no clinical improvement was detected within $24 \mathrm{~h}$, a second dose of tocilizumab was administered. In a few cases, the decision to give tocilizumab was based on treating physician discretion.

\section{Results}

\section{Demographics and clinical characteristics}

Twenty-eight cancer patients tested positive for SARS$\mathrm{CoV}-2$. Of those, 16 (57\%) presented to the ED during the study period for a total of $18 \mathrm{ED}$ encounters, while $12(43 \%)$ did not visit the ED. Fifteen of the 16 patients that presented to the ED were hospitalized due to COVID-19, and only two of those died (Figure 1). The patients' demographics and clinical characteristics are summarized in Table 1, there was no statistically significant difference between the ED and no ED visit groups. Further breakdown of the disease stage and specific treatment for each patient is listed in Table S1. The most common type of malignancies were multiple myeloma (18\%), gastrointestinal tumors (18\%) and breast cancer (14\%), and there was no difference between solid organ tumors and hematological malignancies. Patients on active treatment also did not significantly differ when compared to those who had not received treatment in the 30 days prior to COVID-19 testing.

Symptoms are detailed in Table 2, and shortness of breath was the only symptom that significantly varied $(\mathrm{P}=0.009)$ between the two groups (ED versus non-ED).

\section{Laboratory and radiologic findings}

The ED patients' laboratory values are given in Table 3. Patients who received tocilizumab during their hospitalization had a lower absolute lymphocyte count at presentation $(2.77 \pm 1.86$ versus $4.70 \pm 2.34)$ than those who did not get this intervention. Lymphopenia was noted in $44 \%$ of all encounters. Additionally, abnormal findings were present in $89 \%$ of chest radiographs ordered and $100 \%$ of computed tomography scans ordered.

All patients' swab specimens were negative for other respiratory viruses. One patient whose nasopharyngeal swab specimens tested negative for SARS-CoV-2 on two occasions had a bronchoalveolar lavage specimen positive for the virus.

\section{ED interventions}

The most common ED intervention, initiated at the time of evaluation and before the SARS-CoV-2 test was resulted, was intravenous antibiotics (78\%). The most commonly used antibiotics were the combination of cefepime and vancomycin $(56 \%)$ followed by cefepime and linezolid (16\%). Most patients received supplemental oxygen via a nasal cannula or non-rebreather mask, and one patient required intubation in the ED.

\section{Inpatient interventions}

Among the 15 patients who were hospitalized (Table 4) the most common medications administered included azithromycin (93\%), hydroxychloroquine (73\%), and tocilizumab (53\%). Half of the patients who received tocilizumab required mechanical ventilation and seven out of eight were discharged. We also noticed that patients with severe COVID-19 who required ventilatory support and developed acute respiratory distress syndrome (ARDS) had durable responses to intravenous steroids. 
Table 1 Study population demographics

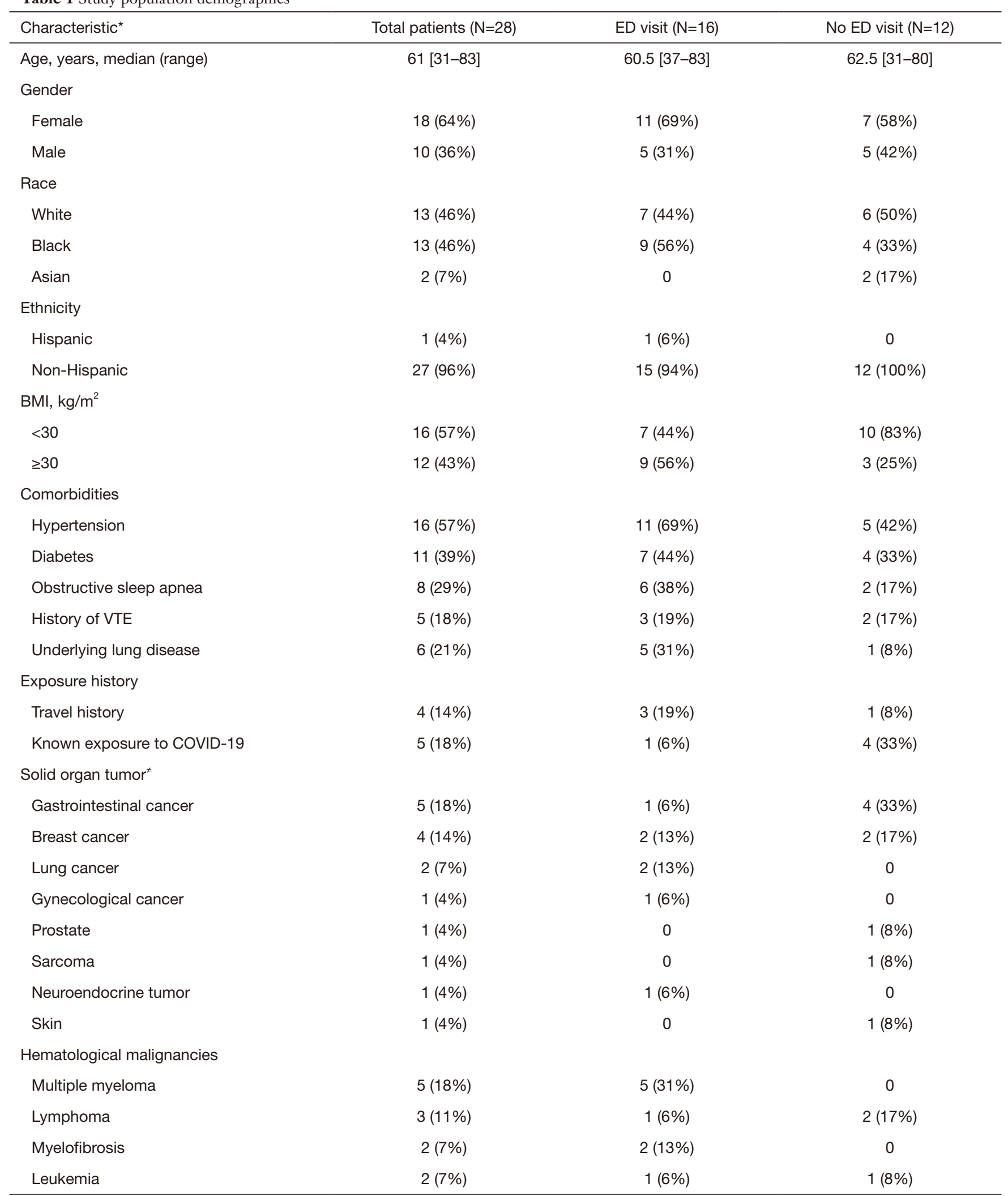

Table 1 (continued) 
Table 1 (continued)

\begin{tabular}{lccc}
\hline Characteristic* $^{*}$ & Total patients (N=28) & ED visit (N=16) & No ED visit (N=12) \\
\hline Disease status & $18(64 \%)$ & $11(69 \%)$ & $7(58 \%)$ \\
Active & $10(36 \%)$ & $5(31 \%)$ & $5(42 \%)$ \\
No active disease & $16(57 \%)$ & $10(63 \%)$ & $6(50 \%)$ \\
Active treatment within 30 days $^{\epsilon}$ & & & \\
\hline
\end{tabular}

*, no statistically significant difference was found for any of the variables. ${ }^{\neq}$, analyses by grouping on hematological versus solid tumors was non-significant. ${ }^{\epsilon}$, one patient was only receiving radiation. ED, emergency department; BMI, body mass index; COVID-19, coronavirus disease 2019; VTE, venous thromboembolism.

Table 2 Symptoms leading to testing and duration of symptoms

\begin{tabular}{|c|c|c|}
\hline Symptoms & ED visit $(\mathrm{N}=18)^{\#}$ & No ED visit $(\mathrm{N}=12)$ \\
\hline \multicolumn{3}{|l|}{ Symptoms leading to testing } \\
\hline Fever & $12(67 \%)$ & $7(58 \%)$ \\
\hline Shortness of breath* & $12(67 \%)$ & $2(17 \%)$ \\
\hline Cough & 9 (50\%) & $8(67 \%)$ \\
\hline Headache & $4(22 \%)$ & $1(8 \%)$ \\
\hline Diarrhea & $3(17 \%)$ & $1(8 \%)$ \\
\hline Congestion & $2(11 \%)$ & 0 \\
\hline Sore throat & $1(6 \%)$ & $2(17 \%)$ \\
\hline Runny nose & $1(6 \%)$ & $4(33 \%)$ \\
\hline Lethargy & $1(6 \%)$ & $0(0 \%)$ \\
\hline Anosmia & 0 & $3(25 \%)$ \\
\hline Dysgeusia & 0 & $1(8 \%)$ \\
\hline Duration of symptoms prior to testing, median [range], days ${ }^{1}$ & $4[1-23]$ & $4[0-20]$ \\
\hline
\end{tabular}

*, $\mathrm{P}=0.009$. ", 16 patients presented to the ED for a total of 18 ED visits, with two patients presenting twice. ${ }^{1}$, patients who were asymptomatic were coded as " 0 " days. ED, emergency department.

\section{Clinical outcomes}

One patient was evaluated and discharged from the ED the same day. A second patient was initially discharged from the ED and returned requiring hospitalization, while a third patient returned to the ED after hospital discharge and was discharged home the same day from the ED. There was only one admission from the cohort that did not present to the ED, and it was for an elective procedure. This patient was tested in preparation for the procedure and found to be positive for SARS-CoV-2 infection.

DNR orders were initiated for eight patients as early as two days after their presentation to the ED. Two of these patients died; one patient died three days after the initiation of the DNR order, and the other patient died four days after the initiation of the DNR order. Three out of four patients that developed ARDS and needed ventilatory support had a 
Table 3 Vital signs and laboratory findings of 16 patients with 18 ED encounters

\begin{tabular}{|c|c|}
\hline Parameters & Numbers \\
\hline \multicolumn{2}{|l|}{ Vital signs } \\
\hline Pulse oximetry $\leq 95 \%$ & $12(67 \%)$ \\
\hline Pulse oximetry \%, median [range] & 95 [91-97] \\
\hline Heart rate $\geq 100$ beats per minute & $8(44 \%)$ \\
\hline Heart rate bpm, median [range] & $99[87-110]$ \\
\hline Temperature $\geq 100.4^{\circ} \mathrm{F}$ & $5(28 \%)$ \\
\hline Respiratory rate $\geq 20$ breaths per minute & $5(28 \%)$ \\
\hline Blood pressure $\leq 90 / 60 \mathrm{~mm} / \mathrm{Hg}$ & $1(6 \%)$ \\
\hline \multicolumn{2}{|l|}{ Laboratory values } \\
\hline WBC elevated (>11.0 k/ $\mu \mathrm{L})$ & $3(17 \%)$ \\
\hline WBC decreased $(<4.0 \mathrm{k} / \mu \mathrm{L})$ & $3(17 \%)$ \\
\hline 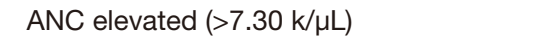 & $3(17 \%)$ \\
\hline ANC decreased $(<1.70 \mathrm{k} / \mu \mathrm{L})$ & $3(17 \%)$ \\
\hline $\begin{array}{l}\text { Hgb decreased }[<12.0 \mathrm{~g} / \mathrm{dL} \text { (women); } \\
<14.0 \mathrm{~g} / \mathrm{dL} \text { (men)] }\end{array}$ & $12(67 \%)$ \\
\hline Platelet count decreased $(<140 \mathrm{k} / \mu \mathrm{L})$ & $6(33 \%)$ \\
\hline LDH elevated (>225 U/L) ${ }^{a}$ & $8 / 10(80 \%)$ \\
\hline ALC decreased $(<1.0 \mathrm{k} / \mu \mathrm{L})$ & $10(56 \%)$ \\
\hline 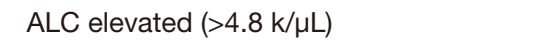 & $1(6 \%)$ \\
\hline AST elevated (>33 U/L) & 7 (39\%) \\
\hline ALT elevated (>32 U/L) & 7 (39\%) \\
\hline Creatinine elevated (>0.95 mg/dL) & $9(50 \%)$ \\
\hline D-dimer elevated $(>0.50 \mathrm{mcg} / \mathrm{mL} \text { FEU) })^{\mathrm{a}}$ & $8 / 14(57 \%)$ \\
\hline CRP elevated $(>10 \mathrm{mg} / \mathrm{L})^{\mathrm{a}}$ & $8 / 10(80 \%)$ \\
\hline Procalcitonin elevated $(>0.08 \mathrm{ng} / \mathrm{mL})^{a}$ & $4 / 8(50 \%)$ \\
\hline Troponin T elevated $(>19 \mathrm{ng} / \mathrm{L})^{a}$ & $1 / 9(11 \%)$ \\
\hline
\end{tabular}

${ }^{\mathrm{a}}$, data are for the indicated number of ordered tests only. ED, emergency department; ANC, absolute neutrophil count; ALC, absolute lymphocyte count; ALT, alkaline phosphatase; AST, aspartate aminotransferase; CRP, C-reactive protein; FEU, fibrinogen equivalent units; $\mathrm{Hgb}$, hemoglobin; $\mathrm{LDH}$, lactate dehydrogenase; WBC, white blood cell count.

DNR order placed after initiation of mechanical ventilation. All of the patients that required mechanical ventilation were eventually discharged home. Of the 16 patients that presented to the ED 14 survived.
Table 4 Inpatient management of 15 patients at least 14 days after admission

\begin{tabular}{lc}
\hline Management data & Number \\
\hline Systemic agents & $15(100 \%)$ \\
Antimicrobials ${ }^{*}$ & $11(73 \%)$ \\
Hydroxychloroquine & $8(53 \%)$ \\
Tocilizumab & $6(40 \%)$ \\
Vitamin C & $5(33 \%)$ \\
Corticosteroids & $3(20 \%)$ \\
Anakinra & $3(20 \%)$ \\
Zinc & \\
Inpatient interventions & $4(27 \%)$ \\
Intubation & $2.00 \pm 1.41$ \\
Mean time to intubation \pm SD, days & $3.33 \pm 3.215$ \\
Mean time to vasopressor use \pm SD, days & \\
Outcomes & \\
Mean time from presentation to DNR & \\
initiation \pm SD, days & \\
Mean time from DNR initiation to death \pm SD, & $3.5 \pm 0.70$ \\
days & \\
Mean hospitalization time \pm SD (range), days & $10.9 \pm 10.7[2-39]$ \\
are for 8 patients for whom DNR orders were initiated during the \\
period. DNR, do-not-resuscitate order; SD, standard deviation.
\end{tabular}

\section{Discussion}

Cancer patients are thought to have an increased vulnerability to COVID-19 due to their compromised immune system, and have been reported to have high mortality rates (3-5). Our study showed that although $57 \%$ of the patients presented to the $\mathrm{ED}$, most of these patients were discharged, which suggests better outcomes than previously reported in the literature. Symptoms leading up to the diagnosis of COVID-19 were similar to those reported in the general population (3,5-9). and in cancer patients without COVID-19 infection (11). However, the presence of dyspnea, hypoxemia and characteristic radiologic findings may facilitate prompt identification of those infected and may trigger early goals of care discussion. 
In our cohort only one of the patients with a severe outcome, was noted to have metastatic disease. Active cancer treatment and stage of disease have been previously associated with worse outcomes (5). This is an important aspect to consider in cancer patients as therapies for COVID-19 may have potential interactions with commonly used antineoplastic drugs (12). Both patients who died were on chemotherapy, had hypertension, and obstructive sleep apnea. Consistent with previous studies' findings $(5,13)$. our findings suggest that active cancer treatment and hypertension increases patients' vulnerability to COVID-19 (14-18). The role of hormone therapy in SARS-CoV-2 infections has been previously discussed as a having potentially protective effects in cancer patients with COVID-19 (19). However, we did not feel this contributed to our slightly female predominant sample.

We did not find a difference in COVID-19 disease severity when comparing patients with solid tumors versus those with hematologic malignancies. However, all five patients with multiple myeloma required hospitalizations (20). In multiple myeloma patients, plasma cells-terminally differentiated B cells that have an essential function in adaptive immunity (21) —aberrantly accumulate in the bone marrow, causing secondary hypogammaglobulinemia and increasing the risk of infection (22). This immunodeficiency can be aggravated by anti-myeloma treatments; in fact, all the multiple myeloma patients in our series were receiving anti-myeloma treatment at the time of admission to the ED $(23,24)$. Deficiencies in acquired immunity, paired with the negative effects of anti-myeloma therapy, may increase the risk of SARS-CoV-2 infection in myeloma patients.

Co-infections with other pathogens in COVID-19 patients have also been reported (25). Thus, ED physicians in an oncologic setting should consider synchronous infections, including those from opportunistic pathogens (such as Pneumocystis forovecci, Nocardia, and fungal infections). Most patients in our cohort received intravenous antibiotics in the ED for presumed bacterial pneumonia. Radiographic imaging may be helpful in narrowing the differential, and chest $\mathrm{CT}$ has been recommended as the standard method for diagnosing COVID-19 (26). Using RTPCR findings as a reference, Caruso and associates reported that chest CT has a sensitivity of $97 \%$ but a specificity of only $56 \%$ in detecting COVID-19 (27). Radiological findings may be atypical, and ground glass opacities may point to a diagnosis other than COVID-19 (28). In cancer patients, other etiologies should be considered including druginduced pneumonitis, radiation pneumonitis, and metastatic disease $(29,30)$.

Over half of the hospitalized patients had a DNR order written, but three of four patients requiring ventilatory and vasopressor support were made DNR after the patient was intubated. While all four of these patients were discharged, the importance of a goals of care discussion antecedent to the development of a critical illness is paramount (31). When addressed earlier, the patient's wishes may be respected, and the burden of decision making on family members can be alleviated. None of the patients had goals of care discussion in the ED. Thus, especially in those with pre-existing condition such as cancer, the discussion of code status should be initiated early, or at least introduced.

In addition to age, other factors such as disease stage, prognosis, and symptoms should be considered prior to intubation. In those with an established DNR order, the focus of care in the ED should be shifted to symptom management. Oxygen, opioids, and steroids are good interventions for the palliation of dyspnea. Frequent communication with family members using telemedicine modalities should be encouraged. Patients and their family members should be referred to palliative care services, which can provide counseling that can ease the pain of loss and help in the bereavement process.

\section{Limitations}

This study was limited by the small sample size obtained from a single center, which limits its generalizability to larger, more diverse patient population and prevents meaningful inferences from being made. The data was obtained from retrospective chart review, which may present its own inherent limitation, such as possibly missing data (e.g., missing lab values); however, the use of the electronic medical record minimized loss of information. We noticed a slightly higher percentage of females in our cohort, but we attribute this to the small sample size and not the type of malignancy. Our sample size may also be limited due to our institution's swift response in encouraging social distancing, as well as the adherence of cancer patients to these safety precautions. We believe this series highlights the complexities associated with the evaluation pf cancer patients including end of life discussion.

\section{Conclusions}

The majority of cancer patients with COVID-19 infection admitted to the hospital through the ED had good survival. 
We did not notice a difference between cancer types, and active therapy might be a risk factor for more severe disease. A broad differential is important when caring for cancer patients with COVID-19, for infection may co-exist with other concomitant processes. Finally, goals of care discussion should become part of the ED encounter in case further decompensation ensues.

\section{Acknowledgments}

Joseph A. Munch, Senior Scientific Editor at MD Anderson Cancer Center for his editorial help with the manuscript and Kumar Alagappan, MD, Department of Emergency Medicine Chair for his general support.

Funding: This research is supported in part by the National Institutes of Health through MD Anderson's Cancer Center Support Grant (CA016672).

\section{Footnote}

Reporting Checklist: The authors have completed the STROBE reporting checklist. Available at http://dx.doi. org/10.21037/apm-20-1447

Data Sharing Statement: Available at http://dx.doi. org/10.21037/apm-20-1447

Peer Review File: Available at http://dx.doi.org/10.21037/ apm-20-1447

Conflicts of Interest: All authors have completed the ICMJE uniform disclosure form (available at http://dx.doi. org/10.21037/apm-20-1447). EM has received research support from Sanofi, Quest Diagnostics, Novartis, JW Pharma, Merck; consultant fees from Takeda, Celgene, Sanofi, Janssen, GSK and Adaptive Biotechnologies. The other authors have no conflicts of interest to declare.

Ethical Statement: The authors are accountable for all aspects of the work in ensuring that questions related to the accuracy or integrity of any part of the work are appropriately investigated and resolved. This study was conducted in accordance with a clinical research protocol (\# 2020-0348) approved by MD Anderson Cancer Center's Institutional Review Board and the study conformed to the provisions of the Declaration of Helsinki (as revised in 2013). Written informed consent was waived as this was a chart review study.
Open Access Statement: This is an Open Access article distributed in accordance with the Creative Commons Attribution-NonCommercial-NoDerivs 4.0 International License (CC BY-NC-ND 4.0), which permits the noncommercial replication and distribution of the article with the strict proviso that no changes or edits are made and the original work is properly cited (including links to both the formal publication through the relevant DOI and the license). See: https://creativecommons.org/licenses/by-nc-nd/4.0/.

\section{References}

1. World Health Organization. Coronavirus disease (COVID-19) pandemic 2020 [updated April 30,2020; cited 2020 April 30]. Available online: https://covid19.who.int

2. Gosain R, Abdou Y, Singh A, et al. COVID-19 and Cancer: a Comprehensive Review. Curr Oncol Rep 2020;22:53.

3. Guo YR, Cao QD, Hong ZS, et al. The origin, transmission and clinical therapies on coronavirus disease 2019 (COVID-19) outbreak - an update on the status. Mil Med Res 2020;7:11.

4. Onder G, Rezza G, Brusaferro S. Case-Fatality Rate and Characteristics of Patients Dying in Relation to COVID-19 in Italy. JAMA 2020;323:1775-6.

5. Dai M, Liu D, Liu M, et al. Patients with Cancer Appear More Vulnerable to SARS-CoV-2: A Multicenter Study during the COVID-19 Outbreak. Cancer Discov 2020;10:783-91.

6. Huang C, Wang Y, Li X, et al. Clinical features of patients infected with 2019 novel coronavirus in Wuhan, China. Lancet 2020;395:497-506.

7. Li LQ, Huang T, Wang YQ, et al. COVID-19 patients' clinical characteristics, discharge rate, and fatality rate of meta-analysis. J Med Virol 2020;92:577-83.

8. Adhikari SP, Meng S, Wu YJ, et al. Epidemiology, causes, clinical manifestation and diagnosis, prevention and control of coronavirus disease (COVID-19) during the early outbreak period: a scoping review. Infect Dis Poverty 2020;9:29.

9. Chang D, Lin M, Wei L, et al. Epidemiologic and Clinical Characteristics of Novel Coronavirus Infections Involving 13 Patients Outside Wuhan, China. JAMA 2020;323:1092-3.

10. Haimovich AD, Ravindra NG, Stoytchev S, et al. Development and Validation of the Quick COVID-19 Severity Index: A Prognostic Tool for Early Clinical Decompensation. Ann Emerg Med 2020;76:442-53. 
11. Elsayem AF, Merriman KW, Gonzalez CE, et al. Presenting Symptoms in the Emergency Department as Predictors of Intensive Care Unit Admissions and Hospital Mortality in a Comprehensive Cancer Center. J Oncol Pract 2016;12:e554-63.

12. Di Lorenzo G, Di Trolio R, Kozlakidis Z, et al. COVID 19 therapies and anti-cancer drugs: A systematic review of recent literature. Crit Rev Oncol Hematol 2020;152:102991.

13. Zhang L, Zhu F, Xie L, et al. Clinical characteristics of COVID-19-infected cancer patients: a retrospective case study in three hospitals within Wuhan, China. Ann Oncol 2020;31:894-901.

14. Guan WJ, Liang WH, Zhao Y, et al. Comorbidity and its impact on 1590 patients with Covid-19 in China: A Nationwide Analysis. Eur Respir J 2020;55:2000547.

15. Deng SQ, Peng HJ. Characteristics of and Public Health Responses to the Coronavirus Disease 2019 Outbreak in China. J Clin Med 2020;9:575.

16. Chen T, Wu D, Chen H, et al. Clinical characteristics of 113 deceased patients with coronavirus disease 2019: retrospective study. BMJ 2020;368:m1091.

17. Peng YD, Meng K, Guan HQ, et al. Clinical characteristics and outcomes of 112 cardiovascular disease patients infected by 2019-nCoV. Zhonghua Xin Xue Guan Bing Za Zhi 2020;48:450-5.

18. Liu M, He P, Liu HG, et al. Clinical characteristics of 30 medical workers infected with new coronavirus pneumonia. Zhonghua Jie He He Hu Xi Za Zhi 2020;43:209-14.

19. Di Lorenzo G, Buonerba L, Ingenito C, et al. Clinical Characteristics of Metastatic Prostate Cancer Patients Infected with COVID-19 in South Italy. Oncology 2020;98:743-7.

20. Manasanch EE, Mulanovich V, Manzano JG, et al. SARS-CoV-2 in multiple myeloma: initial observation and management. Leukemia and Lymphoma 2020. doi: 10.1080/10428194.2020.1780588.

Cite this article as: Lipe DN, Elsayem A, Cruz-Carreras MT, Thomas J, Feliciano A, Ren J, Gaeta SM, Rajha E, Manasanch E, Kheder E, Brock P, Reyes-Gibby C. Characteristics of cancer patients with COVID-19 in a cancer hospital. Ann Palliat Med 2021;10(2):1763-1771. doi: 10.21037/apm-20-1447
21. Pioli PD. Plasma Cells, the Next Generation: Beyond Antibody Secretion. Front Immunol 2019;10:2768.

22. Dosani T, Mailankody S, Korde N, et al. Host-related immunodeficiency in the development of multiple myeloma. Leuk Lymphoma 2018;59:1127-32.

23. Pratt G, Goodyear O, Moss P. Immunodeficiency and immunotherapy in multiple myeloma. Br J Haematol 2007;138:563-79.

24. Blimark C, Holmberg E, Mellqvist UH, et al. Multiple myeloma and infections: a population-based study on 9253 multiple myeloma patients. Haematologica 2015;100:107-13.

25. Zhou F, Yu T, Du R, et al. Clinical course and risk factors for mortality of adult inpatients with COVID-19 in Wuhan, China: a retrospective cohort study. Lancet 2020;395:1054-62.

26. Li Y, Xia L. Coronavirus Disease 2019 (COVID-19): Role of Chest CT in Diagnosis and Management. AJR Am J Roentgenol 2020;214:1280-6.

27. Caruso D, Zerunian M, Polici M, et al. Chest CT Features of COVID-19 in Rome, Italy. Radiology 2020;296:E79-E85.

28. Moujaess E, Kourie HR, Ghosn M. Cancer patients and research during COVID-19 pandemic: A systematic review of current evidence. Crit Rev Oncol Hematol 2020;150:102972.

29. Kanne JP, Yandow DR, Meyer CA. Pneumocystis jiroveci pneumonia: high-resolution CT findings in patients with and without HIV infection. AJR Am J Roentgenol 2012;198:W555-61.

30. Delaunay M, Cadranel J, Lusque A, et al. Immunecheckpoint inhibitors associated with interstitial lung disease in cancer patients. Eur Respir J 2017;50:1700050.

31. Fadul N, Elsayem AF, Bruera E. Integration of palliative care into COVID-19 pandemic planning. BMJ Support Palliat Care 2021;11:40-4. 
Table S1 Stage of disease and cancer treatment for 28 cancer patients with COVID-19

\begin{tabular}{|c|c|c|c|c|c|c|}
\hline Malignancy class & Cancer treatment at the time of SARS-CoV-2 diagnosis* & Cancer type & Cancer status & Hospitalization & $\begin{array}{c}\text { Days of } \\
\text { hospitalization }\end{array}$ & $\begin{array}{l}\text { Death related to } \\
\text { SARS-CoV-2 }\end{array}$ \\
\hline \multicolumn{7}{|l|}{ Solid tumor } \\
\hline \multicolumn{7}{|l|}{ Lung cancer } \\
\hline Patient 1 & None & Adenocarcinoma of lung & Remission & Yes & 2 & No \\
\hline Patient 2 & None & Adenocarcinoma of lung & Stage IA & No & 0 & No \\
\hline \multicolumn{7}{|l|}{ Breast cancer } \\
\hline Patient 1 & None & Invasive ductal carcinoma & Remission & Yes & 39 & No \\
\hline Patient 2 & Bevacizumab & Invasive ductal carcinoma & Metastatic & Yes & 6 & No \\
\hline Patient 3 & Capecitabine & Infiltrating carcinoma of breast & Metastatic & No & 0 & No \\
\hline Patient 4 & Pertuzumab , trastuzumab, tamoxifen & Infiltrating carcinoma of breast & Stage IA & No & 0 & No \\
\hline \multicolumn{7}{|c|}{ Gastrointestinal tumor } \\
\hline Patient 1 & None & Rectal cancer & Metastatic & Yes & 6 & Yes \\
\hline Patient 2 & None & Adenocarcinoma of the pancreas & Stage IIB & No & 0 & No \\
\hline Patient 3 & None & Adenocarcinoma of the cecum & Stage IIB & No & 0 & No \\
\hline Patient 4 & Bevacizumab with irinotecan, leucovorin, 5-flourouracil & Adenocarcinoma of the sigmoid colon & Metastatic & No & 0 & No \\
\hline Patient 5 & None & Liver cell carcinoma & Stage IB & No & 0 & No \\
\hline \multicolumn{7}{|c|}{ Gynecologic cancer } \\
\hline Patient 1 & Cisplatin, radiation therapy & Mixed endometrial cancer & Stage IIIB & Yes & 5 & Yes \\
\hline \multicolumn{7}{|l|}{ Prostate cancer } \\
\hline Patient 1 & None & Prostate cancer & Remission & No & 0 & No \\
\hline \multicolumn{7}{|c|}{ Neuroendocrine tumor } \\
\hline Patient 1 & None & Neuroendocrine tumor of nasal cavity & Remission & Yes & 5 & No \\
\hline \multicolumn{7}{|l|}{ Sarcoma } \\
\hline Patient 1 & Stereotactic body radiation therapy & Leiomyosarcoma of retroperitoneum & Stage IIIB & No & 0 & No \\
\hline \multicolumn{7}{|l|}{ Skin cancer } \\
\hline Patient 1 & None & Basal cell carcinoma of skin & Remission & No & 0 & No \\
\hline \multicolumn{7}{|c|}{ Hematologic malignancies } \\
\hline \multicolumn{7}{|l|}{ Myelofibrosis } \\
\hline Patient 1 & Jakafi & Myeloproliferative neoplasm & Active-new diagnosis & Yes & 9 & No \\
\hline Patient 2 & Ruxolitinib and Aranesp & Myelodysplastic/myeloproliferative neoplasm & Active & Yes & 19 & No \\
\hline \multicolumn{7}{|c|}{ Multiple myeloma } \\
\hline Patient 1 & $\begin{array}{l}\text { Bortezomib, dexamethasone, cisplatin, doxorubicin, } \\
\text { cyclophosphamide and etoposide }\end{array}$ & IgA kappa & Relapsed & Yes & 5 & No \\
\hline Patient 2 & Revlimid & IgG lambda & Remission & Yes & 9 & No \\
\hline Patient 3 & Carfilzomib, pomalidomide and dexamethasone & IgG kappa & Relapsed & Yes & 28 & No \\
\hline Patient 4 & $\begin{array}{c}\text { Daratumumab, carfilzomib, cyclophosphamide, } \\
\text { dexamethasone }\end{array}$ & IgA kappa & Relapsed & Yes & 3 & No \\
\hline Patient 5 & Daratumumab, lenalidomide and dexamethasone & lgG kappa & Relapsed & Yes & 13 & No \\
\hline \multicolumn{7}{|l|}{ Leukemia } \\
\hline Patient 1 & None & Chronic lymphoid leukemia & Remission & Yes & 28 & \\
\hline Patient 2 & Ibrutinib & Chronic lymphoid leukemia & Relapsed & No & 0 & No \\
\hline \multicolumn{7}{|l|}{ Lymphoma } \\
\hline Patient 1 & None & Hodgkin lymphoma & Remission & Yes & 4 & No \\
\hline Patient 2 & Rituximab and Ibrutinib & Mantle cell lymphoma & Active & No & 0 & No \\
\hline Patient 3 & None & Diffuse large B-cell lymphoma & Active-new diagnosis & No & 0 & No \\
\hline
\end{tabular}

*, treatment within 30 days prior to diagnosis. 